\title{
Isolated gallbladder hematoma after a blunt abdominal trauma: case report
}

\author{
I-Ting Wang ${ }^{1 *}$, Ming-Tse Tsai ${ }^{1}$, Chun-Yen Huang ${ }^{1}$, Kuang-Chau Tsai ${ }^{1}$, Shih-Hao Wu², Wan-Ching Lien ${ }^{3}$, \\ Jen-Tang Sun ${ }^{1}$
}

From 10th WINFOCUS World Congress on Ultrasound in Emergency and Critical Care

Kuala Lumpur, Malaysia. 16-19 November 2014

\section{Background}

Sonography has played an important role on detection of intraabdominal injuries with a sensitivity of $86 \%$, a specificity of $98 \%$, and an accuracy of $97 \%$ [1]. Negative predictive value achieved about 98\% [1]. However, gallbladder injury is rare with incidence around $2.1 \%[2,3]$ in blunt abdominal trauma [2], and commonly associated with the solid organ injury or abdominal vascular injury [4]. Isolated gallbladder injury were very few[3] including traumatic cholecystitis, gallbladder tear, and gallbladder perforation ...etc. Ultrasound is very sensitive to gallbladder disease. We presented a rare case of isolated gallbladder hematoma after a blunt abdominal trauma which diagnosis by Focused Gallbladder ultrasound.

\section{Case report}

A 29-year-old previous healthy man was a motorcycle driver, and he bumped into another motorcycle one day ago. He visited our emergency department due to progressive right upper abdominal pain. He denied fever or bloody stool. Initial vital signs showed a body temperature of $35.4^{\circ} \mathrm{C}$, a blood pressure of $147 / 86 \mathrm{mmHg}$, and a pulse rate of $56 / \mathrm{min}$. Physical examination revealed right upper abdominal tenderness on palpation with positive of Murphy's sign. No obvious ecchymosis was noted during inspection. The remainder of the physical examination was unremarkable. Laboratory findings revealed an elevated hepatic enzyme level with a serum Glutamic Pyruvic Transaminase (GPT) titer of $68 \mathrm{IU} / \mathrm{L}$. The point of care abdominal sonography was performed and demonstrated heterogenic hyperechoic lesion

\footnotetext{
* Correspondence: ballball0314@gmail.com

'Department of Emergency Medicine, Far Eastern Memorial Hospital, New Taipei City, Taiwan

Full list of author information is available at the end of the article
}

without acoustic shadow in gallbladder. Gallbladder wall is normal and no obvious pericholecystic fluid accumulation (Figure 1). Gallbladder hematoma was impressed. Abdominal computed tomography also showed hyperdense substance in gallbladder without liver injury (Figures 2 and 3). Patient was admitted for conservative treatment, due to patient refused operation. Abdominal pain subsided, and he discharged 3 days after admission. Follow-up sonography after 1-month revealed normal appearance of gallbladder without hyperechoic lesion inside (Figure 4).

\section{Discussion}

Cases of gallbladder injury happen mostly in penetrating abdominal trauma and rarely in blunt trauma $[2,5]$. According to Chad's study, only $2 \%$ of gallbladder injuries were isolated, while in associated injuries, approximate $49 \%$ of them were severely injured with unstable hemodynamic status [4]. All of the gallbladder injuries

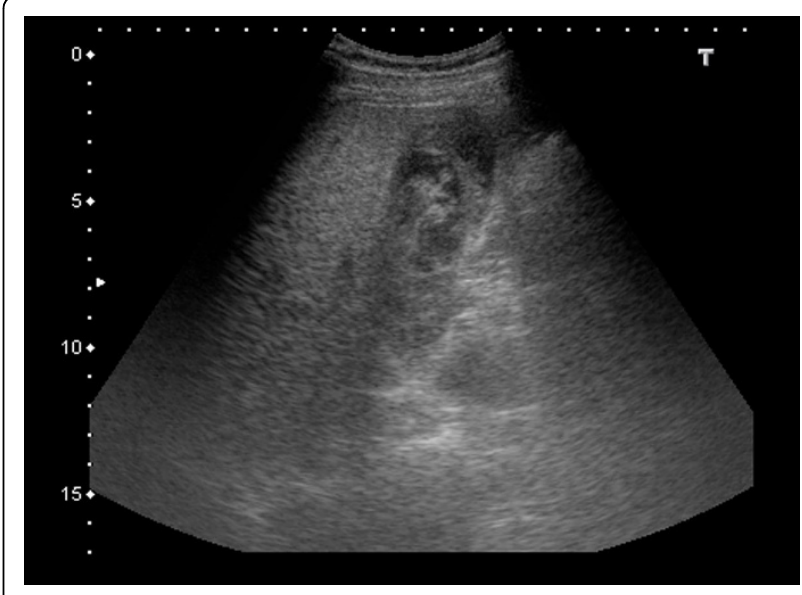

Figure 1 


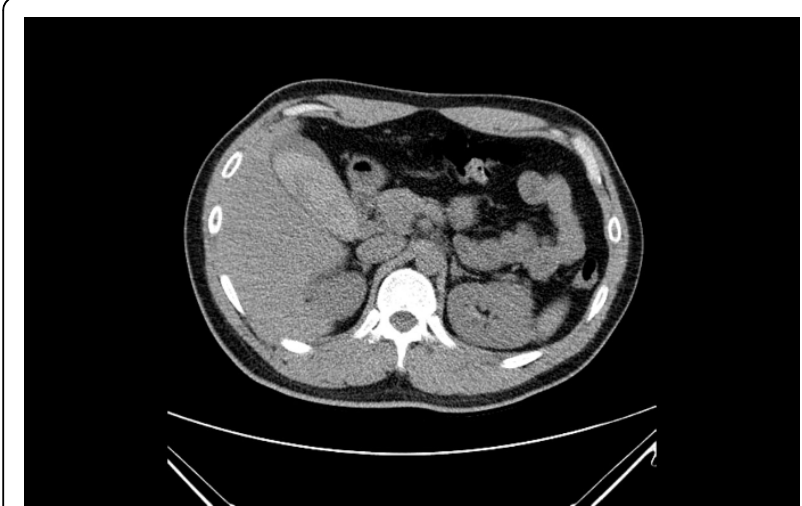

Figure 2

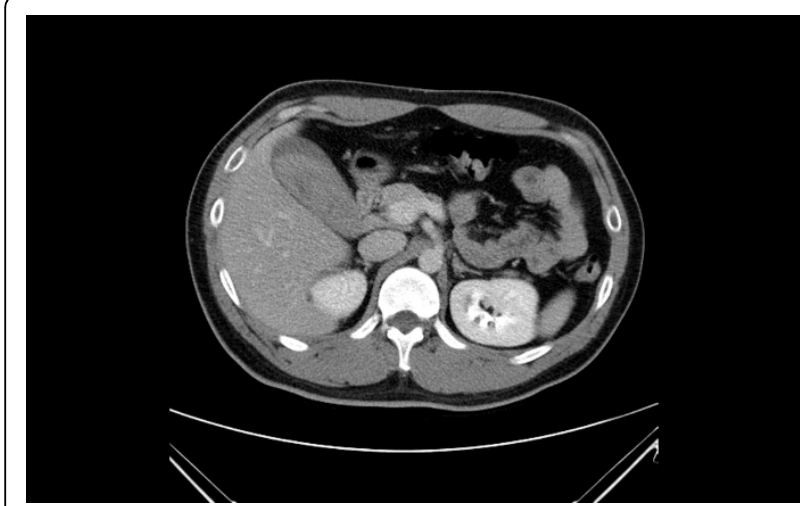

Figure 3

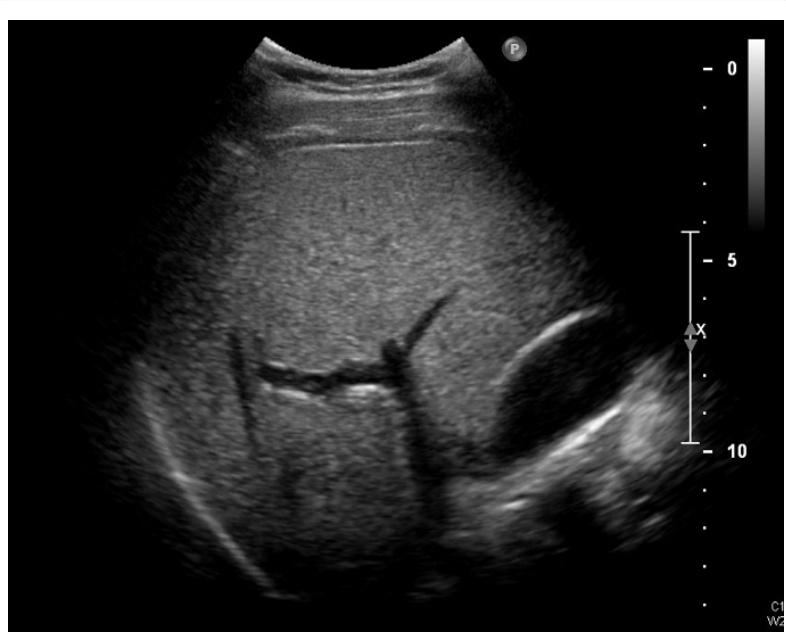

Figure 4

received invasive treatment with $93 \%$ cholecystectomy and $7 \%$ percutaneous drainage [4]. Currently, gallbladder injuries include contusion, laceration, and avulsion. Among these injuries, only contusion type is not communicated to intraabdominal space. Gallbladder contusion was commonly defined as intramural hematoma. However, in our case, the diffuse high-echogenicity in the whole gallbladder demonstrated the possibly rended of muscularis layer of gallbladder; therefore, minor tear of gallbladder should also be concerned. Under such injury force, no presentation of bruise, laceration or abrasion wound is the pitfall on this case. The missing diagnosis should be aware, and surgical exploration should be intervened.

\section{Informed consent}

The study was conducted in accordance with the ethical standards dictated by applicable law. Informed consent was obtained from each owner to enrolment in the study and to the inclusion in this article of information that could potentially lead to their identification.

\section{Authors' details}

'Department of Emergency Medicine, Far Eastern Memorial Hospital, New Taipei City, Taiwan. ${ }^{2}$ Department of Emergency Medicine, Chang-Gung Hospital Lin-Ko Branch, Taoyuen, Taiwan. ${ }^{3}$ Department of Emergency Medicine, National Taiwan University Hospital, Taipei City, Taiwan.

Published: 9 March 2015

\section{References}

1. Matthew O, Dolich MD, Mark G, et al: 2,576 Ultrasounds for Blunt Abdominal Trauma. J Trauma 2001, 50:108-112.

2. James G: Adams. Emergency Medicine, Second.

3. Soderstrom CA, Maekawa K, DuPriest RW Jr, et al: Gallbladder injuries resulting from blunt abdominal trauma: an experience and review. Ann Surg 1981, 193:60-6.

4. Ball Chad G, Dixon Elijah, et al: A decade of experience with injuries to the gallbladder. J of Trauma Manag \& Outcomes 2010, 4:3.

5. Salzman S, Lutfi R, Fishman D, et al: Traumatic rupture of the gallbladder. J Trauma 2006, 61:454-6.

doi:10.1186/2036-7902-7-S1-A27

Cite this article as: Wang et al: Isolated gallbladder hematoma after a

blunt abdominal trauma: case report. Critical Ultrasound Journal 2015

7(Suppl 1):A27.

\section{Submit your manuscript to a SpringerOpen ${ }^{\circ}$ journal and benefit from:}

- Convenient online submission

- Rigorous peer review

- Immediate publication on acceptance

- Open access: articles freely available online

- High visibility within the field

- Retaining the copyright to your article

Submit your next manuscript at $>$ springeropen.com 